\title{
Large incidence variation of Type I diabetes in central-southern Italy 1990-1995: lower risk in rural areas
}

\author{
V. Cherubini ${ }^{1}$, F. Carle ${ }^{2}$, R. Gesuita ${ }^{2}$, A. Iannilli ${ }^{1}$, J. Tuomilehto ${ }^{3}$, F. Prisco ${ }^{4}$, D. Iafusco ${ }^{4}$, E. Altobelli ${ }^{5}$, F. Chiarelli ${ }^{6}$, \\ G. De Giorgi ${ }^{7}$, A. Falorni ${ }^{8}$ \\ ${ }^{1}$ Institute of Paediatrics, University of Ancona, Italy \\ ${ }^{2}$ Department of Epidemiology, Biostatistics and Medical Information Technology, University of Ancona, Italy \\ ${ }^{3}$ Diabetes and Genetic Epidemiology Unit, National Public Health, Helsinki, Finland \\ ${ }^{4}$ Department of Paediatrics, II University of Napoli, Italy \\ ${ }^{5}$ Epidemiological Research Centre, Faculty of Medicine, University of L'Aquila, Italy \\ ${ }^{6}$ Department of Paediatrics, University of Chieti, Italy \\ ${ }^{7}$ Institute of Paediatrics, University of Perugia, Italy \\ ${ }^{8}$ Department of Internal Medicine and Endocrine and Metabolic Sciences, University of Perugia, Italy
}

\section{Abstract}

Aims/hypothesis. To evaluate the relation between the incidence of childhood Type I (insulin-dependent) diabetes mellitus and the degree of urbanization in the central-southern part of Italy.

Methods. The incidence was determined in two areas: area A encompasses 3 regions of central-eastern Italy (Marche, Abruzzo, Umbria), whereas area B encompasses one southern region (Campania). During 1990-1995, 706 children aged 14 or under with insulin-dependent diabetes mellitus of recent onset were registered. The completeness of the case ascertainment in the registries analysed separately for each region was high, ranging from $96.3 \%$ to $99 \%$.

Results. The age-standardized incidence was higher in area A (9.6 per 100000 person per year; $95 \%$ con- fidence interval: $8.5-10.8)$ than in area B (5.4 per 100000 person per year; $95 \%$ confidence interval: 4.9-6.0). In both areas the standardized incidence ratios increased with the degree of urbanization (chisquared for trend: area $\mathrm{A}=140, p<0.0001$; area $\mathrm{B}=79, p<0.0001)$. The highest standardized incidence ratios were in the most urban communities. Conclusion/interpretation. This study showed a statistically significant difference in incidence of childhood insulin-dependent diabetes mellitus among different areas of the continental peninsula of Italy. People living in the rural communities appear to have a lower risk. [Diabetologia (1999) 42: 789-792]

Keywords Insulin-dependent diabetes mellitus, Type I diabetes, epidemiology, incidence, childhood, urban, rural.
The incidence of childhood Type I (insulin-dependent) diabetes mellitus shows large geographic differences worldwide. The between-country variation in incidence reported in different continents is greatest in Europe [1]. In Italy, the within-country variation is probably the greatest in the world [2]. The incidence of Type I diabetes in Sardinia is the highest in

Received: 22 December 1998 and in revised form: 10 March 1999

Corresponding author: V. Cherubini MD, Institute of Paediatrics, University of Ancona, via Corridoni 11, I-60123 Ancona, Italy

Abbreviations: ISTAT, National Institute for Statistics; SIR, standardized incidence ratio.
Italy and second highest in the world after Finland [1]. Within the continental peninsula of Italy, where the incidence of Type I diabetes is much lower than in Sardinia, no statistically significant differences in incidence have been reported [2]. Thus far Italian Type I diabetes registries cover only $57 \%$ of children in the population. We do not know therefore what the overall pattern in incidence within the country is and which area has the lowest incidence rate of Type I diabetes in continental Italy.

The variation in incidence implies that there is no uniformity between risk factors operating in different areas. To investigate whether socio-economic factors play a part in the aetiology of Type I diabetes, some studies have compared the incidence between urban and rural areas [3-5]. 
The aims of this study were to assess the incidence of Type I diabetes in children in two areas in the central-southern part of Italy and to evaluate the role of urbanization on the incidence of Type I diabetes.

\section{Subjects and methods}

Study areas and denominator population. The Italian population, today stable with only a relatively small flow of immigration and emigration, comprises a mingle of different cultural and ethnic groups [6]. In the regions included in this study therefore the populations are also not uniform in their genetic background. The incidence of Type I diabetes in this study was determined in two areas with different socio-economic and cultural lifestyle and climatic characteristics. Area A comprises three regions: Marche, Abruzzo and Umbria in centraleastern Italy. Area B is one region, Campania in south-western Italy. The population denominator data were obtained from the 1991 census of the National Institute for Statistics (ISTAT). The number of children under 15 years of age in area A was 518105 and in area B was 1206620.

Case ascertainment. A population-based registry of Type I diabetes in children aged 14 years or under has been available for the regions Marche, Abruzzo, and Campania since 1990 but in Umbria the registry started in 1993. A retrospective validated registration allowed us to also include the children from the years 1990-1992 from the Umbria region in the analysis. The primary case ascertainment was based on hospital admission records. As secondary independent sources of cases, the registries used prescription registries, personal national health system cards needed by each patient to obtain syringes and strips free of charge, summer camp rosters for diabetic children and membership lists of patient associations. The degree of caseascertainment was estimated according to the capture-recapture method [7] for each registry separately and ranged from $96.3 \%$ in Campania to $99 \%$ in the Marche region. Regional registries for Type I diabetes provided anonymous records of the registered patients containing the local identification number, sex, date of birth, date of diagnosis and the municipality of residence of the patient at the time of diagnosis. All registries defined the first insulin injection as the date of diagnosis of Type I diabetes and the municipality where the child had lived at least 6 months before diagnosis as the patient's place of residence. From 1990 to 1995 , a total of 706 children aged 14 or under were diagnosed as having Type I diabetes in these areas together.

Geographical indicators and degree of urbanization. To study the effect of physical environment to the distribution of the incidence of Type I diabetes, we used the urban-rural status of the Italian municipalities, according to the classification proposed by the ISTAT in 1986 [8]. Because of the history of human settle in Italy, ISTAT considered population density alone to be an inadequate criteria for the urban-rural status of the municipalities.

The urban-rural status of the place has been defined according to population density and 12 other socio-economic indicators, such as the proportion of the population employed and of those employed, the number in agriculture, industries or services, the number of people in a family, the number of house owners and the proportion of houses with bathrooms and telephone lines. According to this composite classification ISTAT identified five groups: metropolis, urban, semi-urban, semi-rural and rural municipalities.

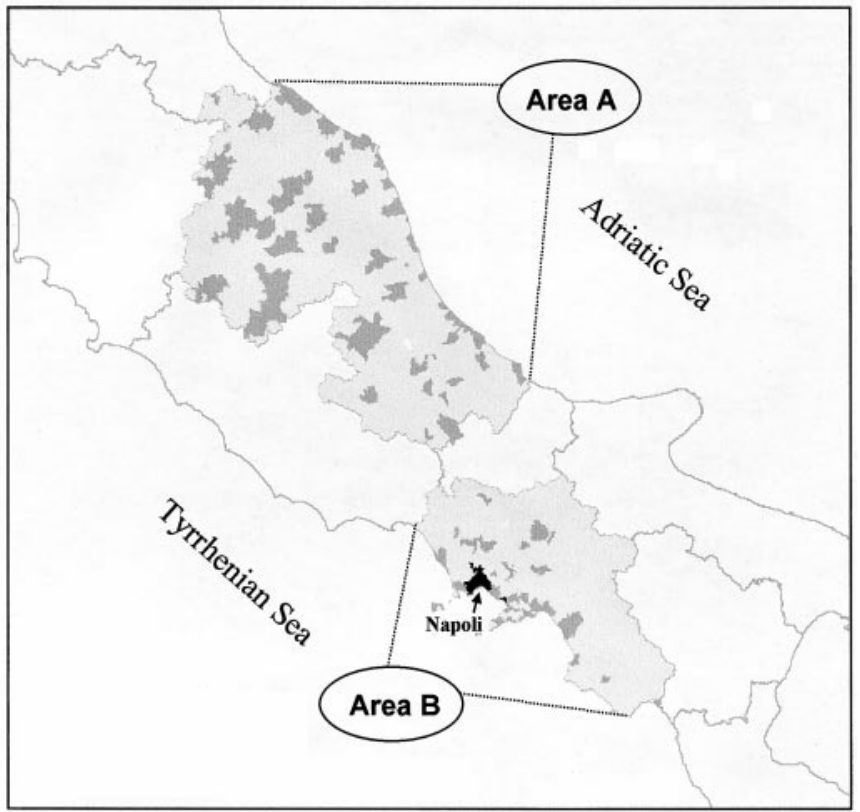

Fig. 1. Geographical disposition of the study areas including the degree of urbanisation. Metropolitan municipalities, urban municipalities, $\square$ semi-urban, semi rural, rural municipalities

Statistical analysis. Cases identified by both primary and secondary sources were used to calculate the age-standardized incidence rates on the world standard population per 100000 persons per year. The $95 \%$ confidence intervals (CI) were estimated assuming the Poisson distribution of the cases. To study geographic indicators and degree of urbanization, the indirect method was used to calculate standardized incidence ratios (SIRs). A ratio of $100 \%$ denotes that the crude incidence of Type I diabetes in the population of interest is equal to the incidence expected if the age-specific incidence rates from the two areas as a whole are applied to that population. Chi-squared test was used to evaluate trend in the SIRs with degree of urbanization [9].

\section{Results}

The age-standardized incidence of Type I diabetes was higher $(p<0.05)$ in area A $(9.6$ per 100000 persons per year; $95 \%$ CI 8.5-10.8) than in area B (5.4 per 100000 persons per year; CI 4.9-6.0). There were no statistically significant differences of incidences among the regions in area A, 9.5 per $100000 /$ year (95\% CI 7.8-11.4) in Marche, 9.4 (95\% CI 7.7-11.2) in Abruzzo and 10.2 (95\% CI 7.9-13.0) in Umbria (the CI overlapped). The municipalities classified as rural were distributed evenly within the area A, whereas a belt of urban municipalities was seen around Napoli in area B (Fig. 1). The SIRs for the incidence of Type I diabetes decreased with the decreasing degree of urbanization in both areas (area $\mathrm{A}, \quad$ chi-square $=140, \quad p<0.0001$; area $\mathrm{B}$, chisquare $=79, p<0.0001)($ Table 1$)$. No differences between sexes were observed. 
Table 1. Standardized Type I diabetes incidence ratios in children aged 14 years (boys and girls together) or under in central-eastern (area A) and in south-western (area B) Italy by the urbanization status of the place of residence

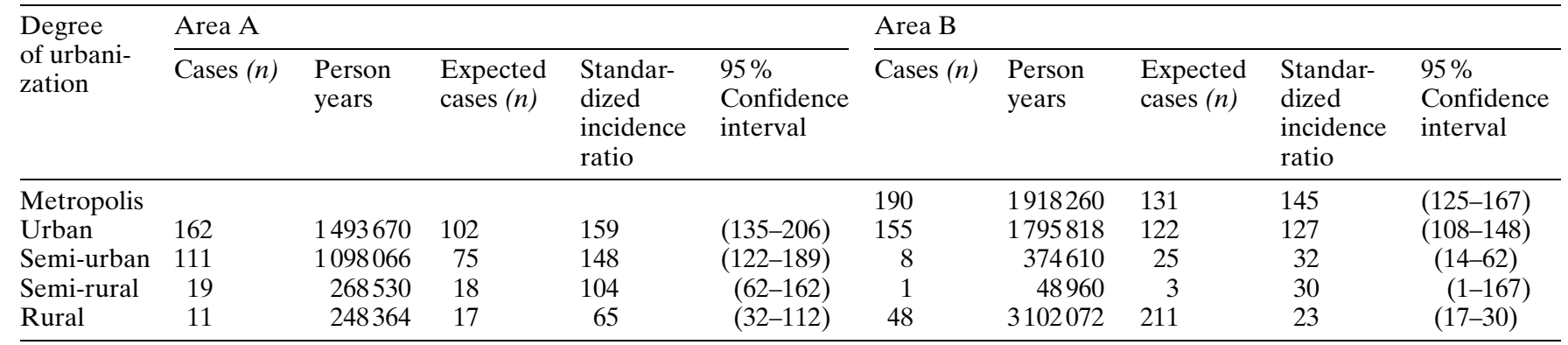

Chi-square for trend: area $\mathrm{A}=140(p<0.0001)$ and area $\mathrm{B}=79(p<0.0001)$

\section{Discussion}

This is a population-based study comparing the incidence of Type I diabetes in two areas of central-eastern and south-western Italy and analysing the effects of the degree of urbanization on incidence. Our findings showed a large difference in the incidence between the study areas. The age-standardized incidence in central-eastern (area A), was about twice as high as that in south-western Italy (area B), moreover there was a pronounced urban-rural gradient in the incidence, similar in both areas.

Very little data on the incidence of Type I diabetes in the Italian-heritage population were reported before the $1980 \mathrm{~s}$, because the standardized registration of cases of Type I diabetes with the evaluation of ascertainment has only been used in studies published after 1990.

Looking at the map (Fig. 1), the geographical distance between the southernmost municipality of area $\mathrm{A}$ and the northernmost municipality of the area $\mathrm{B}$ is very short (less than 30 kilometres), compared with the overall size of the two study areas. Despite this close geographic proximity the incidence of Type I diabetes showed a large difference between area A and B. Geographically they are separated by the mountainous Molise region. Climatic conditions of the two areas of the study are quite different, with a higher average temperature and a lower rainfall in area B. The diet is very similar between the areas.

Concentrations of nitrate in domestic drinking water has been suggested to have a role in the aetiology of Type I diabetes. For both areas included in the study, nitrate concentrations in the drinking water of municipal supplies are less than $50 \mathrm{mg} / \mathrm{l}$, which is within the range recommended by WHO.

The genetic background of the population from central and southern Italy is similar to other northern Mediterranean populations, except Sardinia. It has been suggested that central and southern Italian populations are genetically different [6]. These differences might be the basis for the differences in the incidence of Type I diabetes between the two study areas separated by a mountain range which has obviously limited contacts and genetic mingling between areas.

We have shown that the incidence of Type I diabetes decreased with the decrease in the degree of urbanization in both areas. People living in the rural communities appeared to be protected from Type I diabetes. On the one hand, a higher incidence of the disease among children living in the urban districts has been reported in Wisconsin in the United States and in Novosibirsk in Russia [5]. On the other hand, a low incidence among children living in urban districts has been reported in Scotland, Northern Ireland and Yorkshire in England [3, 10]. In Finland, during 1987-1991, a high incidence was found in the areas with a low population density with a very strong inverse correlation between the population density and the incidence of Type I diabetes [4]. It is difficult and probably incorrect to directly compare our findings with other studies. There are many confounding variables among different countries such as different classification of the urban-rural status, different lifestyle of urban and rural population and sometimes different genetic background. Thus it seems logical to consider studies on urban-rural status of the place of residence of the population as an important tool to obtain hypothesis on the aetiology of diabetes and undertake new research on the environmental and genetic factors.

In an attempt to explain the differences in the incidence of Type I diabetes between urban and rural areas, we can hypothesize that in the urban areas there is probably genetic mingling because of continuos migration whereas the genetic background of the original population is conserved better in rural areas. In rural areas, where populations are at a low genetic risk for Type I diabetes, possibly new genes, "diabetic-prone HLA haplotypes", have not been introduced. Genetic and environmental factors that possibly influence Type I diabetes are under investigation in different high and low risk areas. Recently a national coordinating centre for the inci- 
dence registries of Type I diabetes in Italy has been established.

Acknowledgements. We thank M. Karvonen, C. Sarti and A. Kantar for comments and helpful suggestions on this manuscript. We are also indebted to all clinicians and nurses who notified cases, making their regional register available. The national coordinating centre for the incidence registries of Type I diabetes, RIDI (Register for insulin-dependent diabetes mellitus in Italy) was established 1 January 1997 with the financial support of the National Italian Singer Team (Nazionale Italiana dei Cantanti).

\section{References}

1. Karvonen M, Tuomilehto J, Libman I, LaPorte R for the World Health Organization DIAMOND Project Group (1993) A Review of the recent epidemiological data on the worldwide incidence of Type 1 (insulin-dependent) diabetes mellitus. Diabetologia 36: 883-892

2. Cherubini V, Chiarelli F, Altobelli E, Verrotti A, Carle F (1997) Regional Variability in the Epidemiology of Childhood Diabetes in Italy. J Pediatr Endocrinol Metab 10: 471-478

3. Patterson CC, Carson DJ, Hadden DR on behalf of the Northern Ireland diabetes study group (1996) Epidemiology of childhood IDDM in Northern Ireland 1989-1994: low incidence in areas with highest population density and most household crowding. Diabetologia 39: 1063-1069

4. Karvonen M, Rusanen J, Sundberg M et al. for the childhood diabetes in Finland (DiMe) study group (1997) Regional differences in the incidence of insulin-dependent diabetes mellitus among children in Finland from 1987 to 1991. Ann Med 29: 297-304

5. Shubnikov E, Podar T, Tuomilehto J, Nikitin Y (1992) Low incidence in childhood IDDM in the district of Novosibirsk (Russia). Diabetes Care 15: 915-917

6. Cavalli-Sforza L, Menozzi P, Piazza A (1994) Europe. In: The History and Geography of Human Genes. Princeton University Press, Princeton, New Jersey, pp 268-280

7. Bishop YMM, Fienberg SE, Holland PW (1975) Estimating the size of a closed population. In: Discrete multivariate analysis: theory and practice. MIT Press, Cambridge, Masschusetts, pp 229-256

8. ISTAT (Istituto Nazionale di Statistica) (1986) Classificazioni dei comuni secondo le caratteristiche urbane e rurali. Note e relazioni anno 1986. Vol 2. Grafiche Chicca, Tivoli, Italy

9. Breslow NE, Day AE (1987) Statistical methods in cancer research. Vol. II, IARC Sci Pub 82: 91-103

10. Staines A, Bodansky HJ, McKinney PA et al. (1997) Small area variation in the incidence of childhood insulin-dependent diabetes mellitus in Yorkshire, UK: links with overcrowding and population density. Int $\mathrm{J}$ Epidemiol 26: 1307-1313 